\title{
Pressure Drop Through Porous Media
}

\author{
L. E. BROWNELL, D. C. GAMI, R. A. MILLER, W. F. NeKARVIS
}

\section{Part V}

Fluid flow data are presented for beds of uniformly sized spheres consolidated with resin over a porosity range from 36.4 to $12.3 \%$. The data are analyzed in terms of an effective pore volume and equations are given for predicting pressure drop by use of a friction-factor-Reynolds-number plot.

In Part IV of this study (4) data on beds having porosity ranging from 40 to $90 \%$ were reported. This article presents data on porous beds of consolidated spheres with a porosity range of from 36.4 to $12.3 \%$.

$A$ bed of randomly packed uniformly sized spheres normally has a porosity of about $40 \%$. Beds of lesser porosity can be obtained by several methods: by stacking uniformly sized spheres in a geometrical pattern $(6)$, by compressing beds of uniformly sized spheres by vibration (9), by using mixed sizes (j), and by filling the interstices between the particles. The last method was used in this work.

\section{APPARATUS AND PROCEDURE}

The laboratory apparatus used in obtaining the data for consolidated heds was the same as that pictured in Figure 1 of Part IV of this series (4). Bakelite resin BR 9400 was selected as a suitable consolidating agent which would not shrink appreciably on drying. The bed, composed of 0.208-in.diam. glass spheres, was filled with resin by slowly displacing air upward and taking precautions, such as tapping, to ensure that no air remained trapped in the bed. After a short interval the resin was allowed to drain out of the bed and air was foreed downward through the bed at a pressure of $20 \mathrm{lb}$./sq. in. gauge. The air stream displaced the liquid resin in the open pores but left it (residual saturation) in the interstices. Final drying of the resin was arecolerated by using warm air and heating the bed to $20{ }^{\circ} \mathrm{F}$.

The resin that was left in the bed after the first consolidation reduced the porosity of the bed to $36.4 \%$. The resin coated the spheres with a thin layer and formed a thicker laver at the interstices where the spheres touched. 'Therefore most of the reduction in porosity was obtained by filling the smaller interstices, which contribute less

Parts I through IV of this article appeared in the Transactions of the A merican Institule of Chemical
Engineers and Chemical Engineering Prouress ( $1 \mathrm{to}$ ( $)$.

L. F. Brownell is at the Cniversity of Michlgan. Ann Arbor, Michigan: I). C. Garri at the Instituten of Gas Technology, Chicago, lllinois: R. A. Miller with W. F. Nekarvis with Dow Chemical Company, alidland, Michigan. to flow. With this consolidated bed, a range of flow data from completely laminar to highly turbulent flow was obtained by use of water and Karo-syrup solutions of various viscosities. The porosity of the bed was measured before and after the experimental runs to check any possible compaction as a result of pressure drop. This procedure was repeated with additional coatings of resin to obtain flow data on beds of porosity of 34.2 , $27.0,22.0,19.6$, and $12.3 \%$. Before each additional coating of resin was applied, the bed was inverted to minimize any porosity gradient along the axis of the hed. The data obtained in this manner are plotted in Figure 1 as a modified Reynolds number vs. modified friction factor. The solid line in Figure 1 was previously reported (4) and is for spheres of the same size without consoliclation.

\section{THEORETICAL ANALYSIS}

In a consolidated bed the length of the flow path is greater than the length of the bed, the pore diameter is less than the diameter of the particle, and the linear velocity of the fluid flowing through the consolidated bed is greater than the superficial velocity based on total crosssectional area. In Part II it has been shown that all the pore volume is not effective in contributing to flow (2). It is proposed for the purposes of the analysis that the total pore volume be considered as consisting of two parts: one part, termed the "noneffective" pore volume, consists of the blind channels, dead voids, and fine interstices which do not contribute materially to flow; the other part,

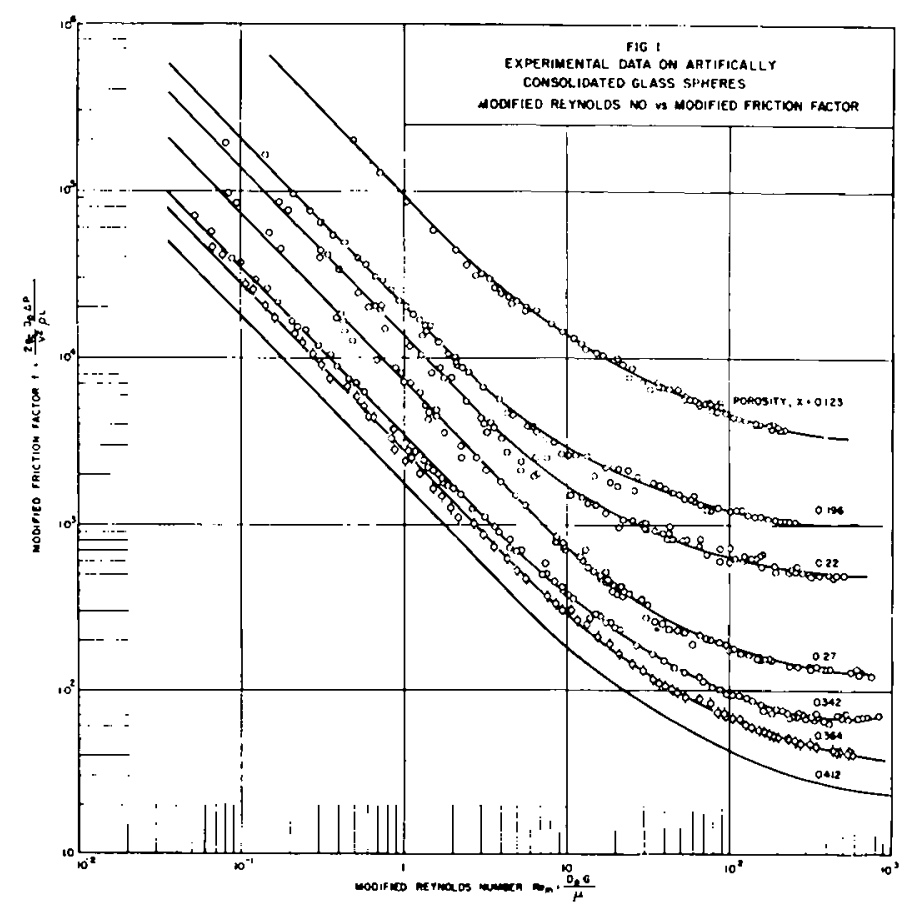


termed the "effective" pore volume, consists of the more open channels which conduct fluid in flow. The distinction between the effective and noneffective pore volumes can be shown by analysis of experimental flow data. Certain assumptions are necessary in order to arrive at the analysis. First it is assumed that the length of the fluid path is proportional to the length of the bed and that changing the porosity by consolidation has no effect on the length of the fluid path, or

$$
L=K_{1} L_{b}
$$

where

$L=$ length of flow path, $\mathrm{ft}$.

$K_{1}=$ proportionality constant

$L_{b}=$ length of bed, $\mathrm{ft}$.

The linear velocity in the bed is directly proportional to the superficial velocity based on total cross-sectional area and inversely proportional to the ratio of flow area to total area. By definition the available area for flow is proportional to the effective pore volume.

$V_{i}=K_{2} V_{s} / X_{e}$

where

$V_{i}=$ linear velocity of fluid, ft./sec.

$V_{s}=$ superficial velocity of fluid based on total cross-sectional area, ft./sec.

$K_{2}=$ proportionality constant

$X_{e}=$ effective porosity, cu. ft. effective voids/cu. ft. total bed

The pore diameter for an unconsolidated bed of uniformly sized, randomly packed particles (such as the experimental bed prior to consolidation) cannot be larger than the particle diameter or the
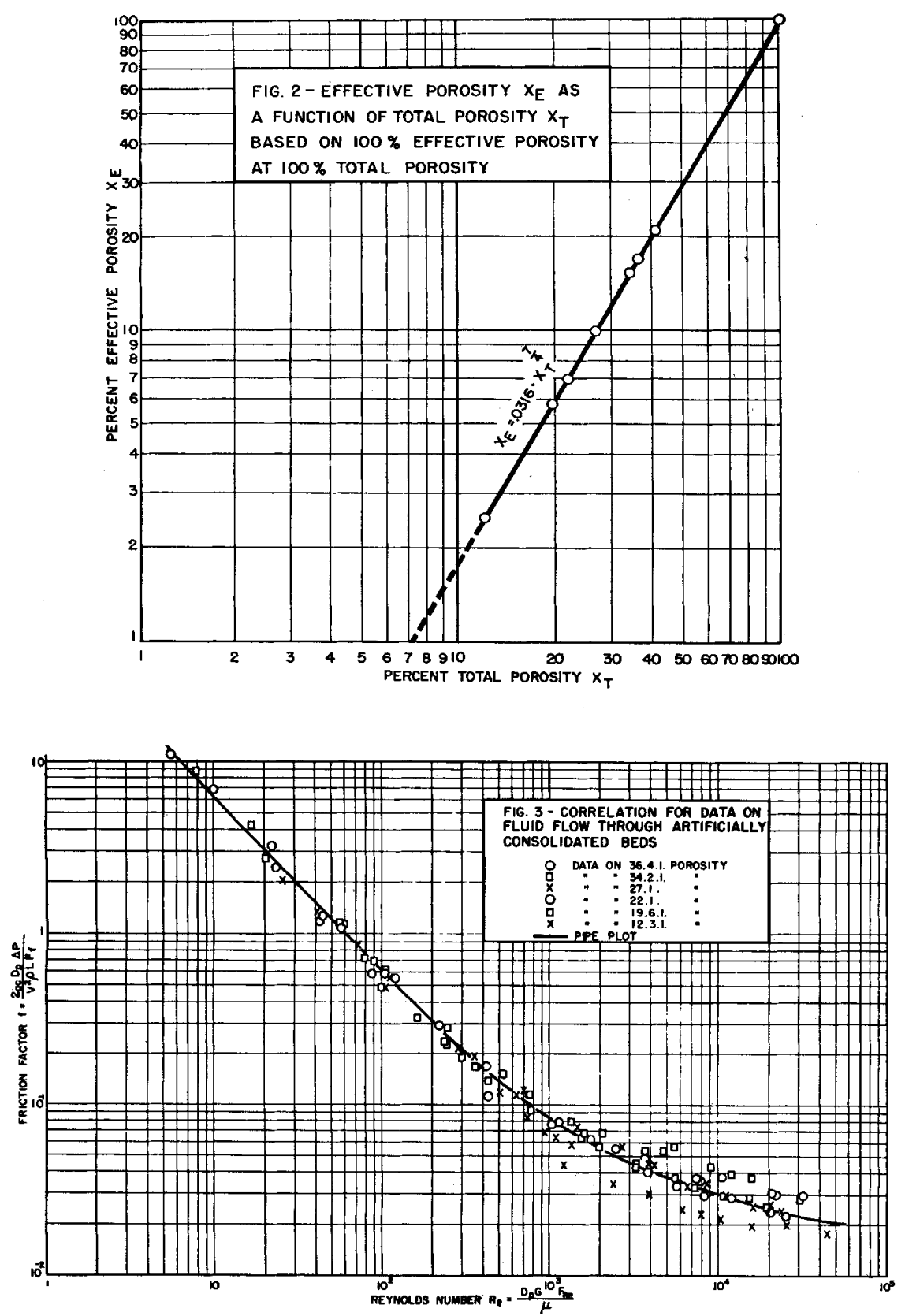

bed would collapse. Also, the pore diameter will not be much smaller than the particle diameter except in the case of selective packing arrangement or consolidation. Consolidation involves decreasing the pore volume. The term pore diameter involves the consideration of an equivalent cylindrical path in the effective pore volume. For a cylinder the diameter is proportional to the square root of the cross-sectional area. Therefore, it is assumed that the pore diameter is a linear function of particle diameter and is proportional to the square root of the area available for flow. Other definitions might be used based on the concept of hydraulic radius, but insufficient data exist at present to indicate the need to include this concept.

$D_{i}=K_{3} D_{p}\left(X_{e}\right)^{1 / 2}$

where

$D_{i}=$ pore diameter, $\mathrm{ft}$.

$K_{3}=$ proportionality constant

$D_{\rho}=$ particle diameter, $\mathrm{ft}$.

By use of the foregoing relationships the Reynolds number and friction factor are defined as follows:

$$
\begin{aligned}
R e & =\frac{D \cdot V \cdot \rho}{\mu} \\
& =\left(K_{3} D_{\rho} X_{e}{ }^{1 / 2}\right) \cdot \frac{\left(K_{2} V_{s}\right)}{X_{e}} \frac{\rho}{\mu} \\
& =\frac{K_{2} K_{3} D_{\rho} V_{s} \rho}{\mu X_{e}{ }^{1 / 2}} \\
f & =\frac{2 g_{\rho} D \Delta p}{L \cdot \rho \cdot V^{2}}=\frac{2 g_{c}\left(K_{3} D_{\rho} X_{e}{ }^{1 / 2}\right)(\Delta p)}{\left(K_{1} L_{b}\right) \cdot \rho \cdot\left(\frac{K_{2} V_{s}}{X_{e}}\right)^{2}} \\
& =\frac{2 g_{c} K_{3}}{K_{1} K_{2}{ }^{2}} \cdot \frac{D_{\rho}(\Delta p) \cdot X_{e}{ }^{5 / 2}}{L_{b} \cdot \rho \cdot V_{s}{ }^{2}}
\end{aligned}
$$

Comparing Equations (4) and (5) with corresponding functions in Part IV shows that the Reynolds number function $F_{R}$ 。 and friction factor function $F_{f}$ can be defined as follows:

$$
\begin{aligned}
F_{R e} & =\frac{K_{2} K_{3}}{X_{e}^{1 / 2}}=K_{4} X_{e}^{-1 / 2} \\
F_{f} & =\frac{K_{1} K_{2}}{K_{3} X_{e}^{5 / 2}}=K_{5} X_{e}^{-5 / 2}
\end{aligned}
$$

In the foregoing relationship the constants $K_{4}, K_{5}$, and the effective porosity $X_{e}$ are unknown for a particular system. However by consolidating the bed the effective porosity $X_{*}$ can be changed while the constants $K_{4}, K_{5}$ remain unchanged. Determination of the functions $F_{R e}$ and $F_{f}$ for consolidated beds and comparison of these functions with the corresponding functions of the unconsolidated bed will eliminate the constants $K_{4}, K_{5}$ : 


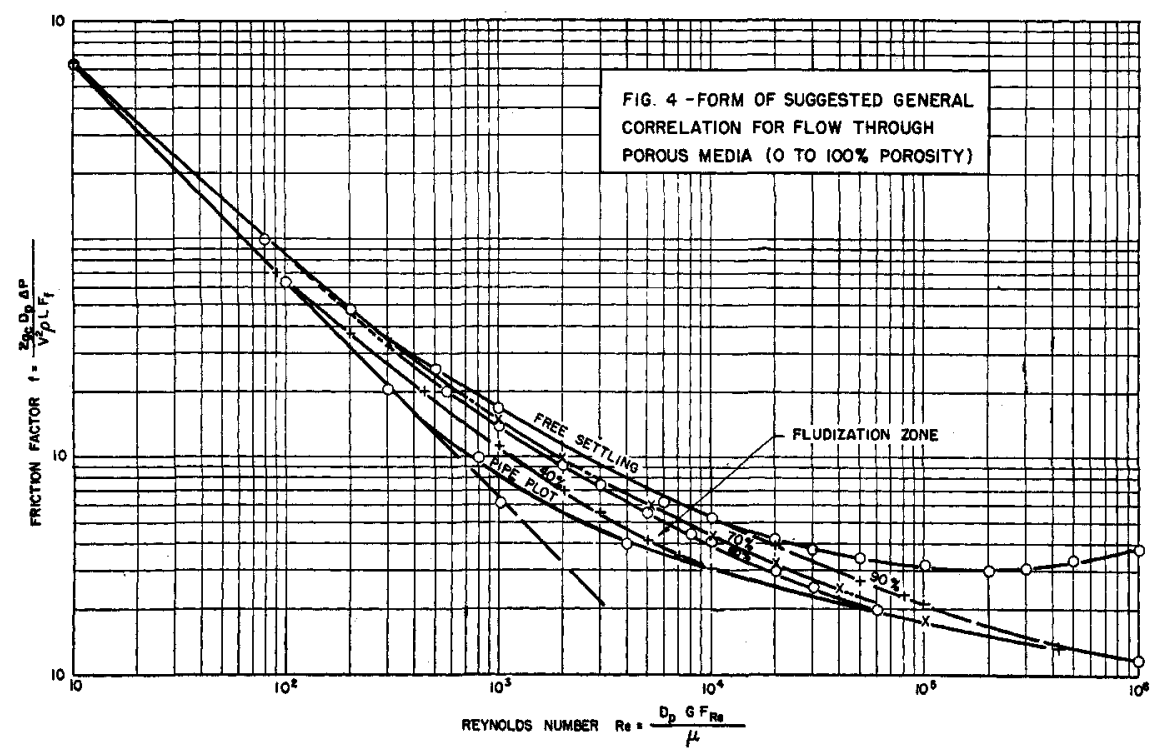

$F_{R_{e}}$ Uncons.

$F_{R_{e}}$ Cons.

$=\frac{K_{4} \text { Uncons. } X_{e}{ }^{1 / 2} \text { Cons. }}{K_{4} \text { Cons. } X_{e}{ }^{1 / 2} \text { Uncons. }}$

$=\frac{X_{e}{ }^{1 / 2} \text { Cons. }}{X_{a}^{1 / 2} \text { Uncons. }}$

$F$, Uncons.

$F_{f}$ Cons.

$$
\begin{aligned}
& =\frac{K_{5} \text { Uncons. } X_{e}{ }^{5 / 2} \text { Cons. }}{K_{5} \text { Cons. } X_{e}{ }^{5 / 2} \text { Uncons. }} \\
& =\frac{X_{e}{ }^{5 / 2} \text { Cons. }}{X_{e}{ }^{5 / 2} \text { Uncons. }}
\end{aligned}
$$

For any value of effective porosity for the unconsolidated bed the corresponding value of effective porosity for the consolidated bed can be calculated from either $F_{R_{e}}$ or $F_{f}$. Obviously a variety of solutions can be obtained depending upon the value of effective porosity for the unconsolidated bed. When effective porosity calculated by this procedure was plotted against total porosity for the different consolidated beds, a straight line was obtained on logarithmic paper with a slope of 1.75 in each case but with an intercept which depended upon the values of $X_{\theta}$ for the unconsolidated bed. Such plots can be extrapolated to the region of high porosity such as exist in fluidized beds and to a limit of $100 \%$ porosity representing free settling of a single particle in an infinite volume of fluid. It was assumed that the value of $X_{\text {e }}$ must be such that at $100 \%$ total porosity the effective porosity must also be $100 \%$. This reasoning makes possible the use of a single line for the relation between the effective and total porosity as shown in Figure 2. The equation of this line is

$$
X_{\bullet} \%=0.0316\left(X_{T} \%\right)^{1.75}
$$

Use of Equation (8) permits the evaluation of the constants $K_{R e}$ and $K_{f}$ of Equations (6) and (7).

$$
\begin{aligned}
F_{R_{\epsilon}} & =182\left(X_{\ell}\right)^{-1 / 2} \\
F_{f} & =2.2 \times 10^{6}\left(X_{\bullet}\right)^{-5 / 2}
\end{aligned}
$$

By use of Equations (8), (9), and (10) the friction factors and Reynolds numbers were calculated from random points of the data and are plotted in Figure 3. This figure indicates the spread of the data based on the correlations. Average deviation ranged from $6.1 \%$ for the bed of $12.3 \%$ porosity to $24.6 \%$ for the bed of $27 \%$ porosity.

\section{DISCUSSION}

Equations (8), (9), and (10) provide a means of predicting pressure drop in beds of consolidated uniformly sized spheres. It is not expected that these relationships will necessarily hold for particles of other shapes or for beds compacted by methods other than consolidation. However additional data on particles of other shapes may make it possible to handle the other cases by the use of an effective porosity. For example data on particles of different shapes might give a family of curves as in Figure 2 with a parameter of shape (sphericity).

The concept of the effective porosity has the intriguing possibility of leading to a relationship which might be general for consolidated beds, unconsolidated beds, fluidized beds, and free settling. Figure 4 shows how such a relationship might look on a friction-factor-Reynolds-number plot. The lower curve represents flow through consolidated beds, unconsolidated beds, and smooth pipes (conduits). The upper curve represents free settling of a single particle. These two curves are expected to have a different shape in the turbulent region because of the increased turbulence resulting from the spin or flutter of the particle in free settling. The lines between the two curves represent fluidized beds and hindered settling. As fluidization of the bed increases, the friction factor would be expected to rise from the friction factor of a fixed bed to the friction factor of free settling. Although Figure 4 was prepared from experimental data, it represents only a suggestion as to how the general relationship might be developed, as there are insufficient data at present to determine the relationship of effective porosity for such a variety of conditions.

Although the specific relationships derived from the limited data will in all probability require revision when new data become available, the concept of effective porosity should be retained because it must be recognized that pore volume has "quality." Earlier correlations (2) for two-phase flow through porous media were based upon an attempt to define empirically the "quality" of the pore volume for the wetting fluid and for the nonwetting fluid. A broad definition of effective pore volume based on a great variety of data should greatly improve the methods of predicting two-phase flow through porous media.

\section{ACKNOWLEDGMENT}

The authors wish to acknowledge support from the funds for faculty research of the Horace H. Rackham School for Graduate Studies, University of Michigan, which made this study possible.

\section{NOTATION}

$D_{i}=$ pipe I. D. or pore diameter, ft.

$D_{p}=$ mean particle diameter, $\mathrm{ft}$.

$g_{c}=$ gravitational const.

$K_{1,2,3,4,5}=$ proportionality constants, dimensionless

$L=$ length of flow, ft.

$L_{b}=$ length of bed, $\mathrm{ft}$.

$\Delta p=$ pressure drop due to flow, $\mathrm{lb} . / \mathrm{sq} . \mathrm{ft}$.

$V_{i}=$ actual fluid linear velocity, ft./sec.

$V_{s}=$ superficial fluid velocity, cu. $\mathrm{ft}$. fluid/(sq. ft. bed area) (sec.)

$X_{\mathrm{e}}=$ effective porosity

$X_{T}=$ total measured porosity

$\mu=$ viscosity of fluid, Ib./(ft.)(sec.)

$\rho=$ fluid density, ft./cu. ft.

\section{UTERATURE CITED}

1. Browneil, L. E., and D. L. Katz, Trans. Am. Inst. Chem. Engrs., 43, No. 10, 527 (1947).

2. -, Chem. Eng. Progr., 43, No. 11, 601 (1947).

3. Loc. cit., 46, No. 8, 415 (1950).

4. Brownell, L. E., C. A. Dickey, and H. S. Dombrowski, Chem. Eng. Progr., 46, No. 8, 415 (1950).

5. Burke, S. P., and W. D. Plumer, Ind. Eng. Chem., 20, 1196 (1928).

6. Martin, J. J., Chem. Eng. Progr., 47, No. 2, 91 (1951).

7. Wilhelm, R. H., and Mooson Kwauk, Chem. Eng. Progr., 44, No. 3, 216 (1948).

8. Fancher, George H., and James A. Lewis, Ind. Eng. Chem., 25, No. 10, 1139 (1933).

9. Oman, A. O., and K. M. Watson, Natl. Petroleum News, 36, No. 44, R 795 (November, 1944)

10. Symposium on Fluidization, Ind. Eng. Chem., 41, 1099 (1949).

Presented at A.I.Ch.E. San Francisco meeting 